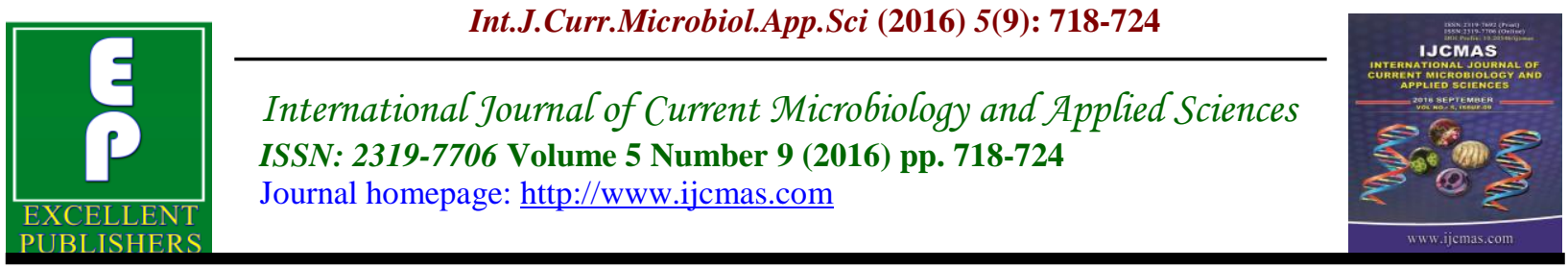

Original Research Article

http://dx.doi.org/10.20546/ijcmas.2016.509.082

\title{
Sclerostin and IL-1Ra in Rheumatoid Iraqi Patients after Biological Therapy
}

\author{
Sanan Th. Abdalwahab ${ }^{1 *}$, Haider Sabah Kadhim ${ }^{2}$, \\ Alauldeen Mudhafar Zubair Alqasim ${ }^{3}$ and Faiq I. Gorial ${ }^{4}$ \\ ${ }^{1}$ College of Medicine, Al-Mustansiriya University, Baghdad, Iraq \\ ${ }^{2}$ College of Medicine, Al-Nahrain University, Baghdad, Iraq \\ ${ }^{3}$ Department of Pathology, College of Medicine, Al-Mustansiriya University, Baghdad, Iraq \\ ${ }^{4}$ Consultant Rheumatologist, Department of Medicine, College of Medicine, Baghdad \\ University, Baghdad, Iraq \\ *Corresponding author
}

\begin{tabular}{|c|c|}
\hline & A B S T R A C T \\
\hline Keywords & \multirow{4}{*}{$\begin{array}{l}\text { Wnt pathway important in control of the bone formation through the regulation of } \\
\text { osteoblast activity, and sclerostin is an important in the regulator of the Wnt } \\
\text { pathway by blocking Wnt binding to its receptor and thereby inhibiting bone } \\
\text { formation. Blockage of Wnt antagonists such as sclerostin will trigger repair or } \\
\text { even healing of bone erosion. Recently show that IL-1Ra has been given important } \\
\text { role in therapeutic and pathogenesis of Rheumatoid arthritis (RA). This study } \\
\text { planned to evaluate the level of serum sclerostin and level of serum IL-1Ra, in } \\
\text { addition to correlate the level of serum sclerostin and IL-1Ra with disease activity } \\
\text { by (CDAI or DAS28) in thirty RA Iraqi patients treated with biological therapy } \\
\text { (Etanercept). The results show that sclerostin level within normal range in healthy } \\
\text { and patients but higher in healthy than patients with biological treatment, also IL- } \\
\text { 1Ra within normal range in healthy and patients but higher in healthy than patients } \\
\text { with biological treatment significant difference ( }<<0.05) \text {. }\end{array}$} \\
\hline $\begin{array}{l}\text { Rheumatoid } \\
\text { arthritis, } \\
\text { sclerostin, } \\
\text { IL-1Ra, } \\
\text { pathogenesis and } \\
\text { etanercept. }\end{array}$ & \\
\hline Article Info & \\
\hline $\begin{array}{l}\text { Accepted: } \\
\text { 25 August } 2016 \\
\text { Available Online: } \\
\text { 10 September } 2016\end{array}$ & \\
\hline
\end{tabular}

\section{Introduction}

RA is an autoimmune disease with both articular and extra-articular involvement. Sclerostin is a protein that in humans has been identified as an inhibitor of the pathway and leads to decreased bone formation. The $\mathrm{Wnt} / \beta$-catenin signaling pathway has well-recognized roles in embryology and development, and is emerging as a critical regulator of bone and cartilage homeostasis in adult. Canonical
Wnt signaling is initiated by binding to frizzled receptors and co-receptors 'LDL receptor-related proteins 5 and 6' (LRP5/6) which leads to $\beta$-catenin stabilization, nuclear translocation and activation of target genes such as Wnt-induced signaling protein-1 (WISP-1) (Blom et al., 2010). Wnt signaling is modulated by soluble antagonists including dickkopf-1 (Dkk1), secreted frizzled-related proteins (sFRPs), 
and sclerostin (SOST). There is little information on changes in SOST in arthritis, with a reduction in the number of SOSTpositive osteocytes noted in association with increased cortical bone density in the femoral neck of patients with hip osteoarthritis (OA) (Power et al., 2010), and in zygapophyseal joints with OA and ankylosing spondylitis (Appel et al., 2009). Previously it was reported that serum levels of sclerostin and Dkk-1 increase in patients with juvenile idiopathic arthritis (JIA) and tumor necrosis factor (TNF- $\alpha$ ) contributes to their increase (Aletaha et al., 2010).

Inflammatory factors such as TNF-alpha have also been shown to reduce osteoblast activity, thereby inhibiting the formation of new bone. Although anti-resorptive approaches, such as bisphosphonates, denosumab, IL-1 receptor antagonist, and TNF-alpha antibody have been effective in slowing or blocking inflammation-induced bone loss, they have shown a limited capacity to restore lost bone. Interleukin 1 receptor antagonist (IL-1Ra) is a naturally occurring IL-1 inhibitor, acting as a "receptor antagonist", which blocks IL-1 mediated signal transduction. In 1990 IL$1 \mathrm{Ra}$ was cloned and later on, a large numbers of studies led to disclosure of the crucial importance of the imbalance between IL-1 and IL-1Ra in the pathogenesis of RA.

\section{Materials and Methods}

Thirty RA patients diagnosed according to the 2010 ACR/EULAR classification criteria $^{5}$ were recruited from consultation of Baghdad teaching hospital in medical city. The inclusion criteria in the study were an inadequate response to one diseasemodifying anti rheumatic drug and patients were taken anti-TNF $\alpha$ therapy. Thirty age and sex matched apparently healthy subjects were included as a control group. All patients underwent full medical history taking and clinical examination with special attention to tender joint count (TJC), swollen joint count (SJC) and morning stiffness. Patients who had Paget disease, multiple myeloma, breast cancer, bone metastasis and patients who were receiving biological treatment in the form of TNF- $\alpha$ inhibitors during the last 6 months were excluded from this study. Disease activity score (DAS28) was assessed and considered low (DAS28 $\geqslant 2.6-<3.2)$ moderate $(\geqslant 3.2-$ $<5.1)$, high $(\geqslant 5.1)$ and DAS28 $<2.6$ as remission (Wolfe, 2002). Modified Health assessment questionnaire (MHAQ) was calculated; eight activities were rated as $0=$ without any difficulty, $1=$ with some difficulty, 2 = with much difficulty, and $3=$ unable to do. MHAQ scores were divided into categories of mild (MHAQ $<1.3)$, moderate $(1.3<\mathrm{MHAQ}<1.8)$ and severe (MHAQ >1.8) functional losses (Eggelmeijer et al., 1993).

Laboratory evaluation included complete blood count (CBC), erythrocyte sedimentation rate (ESR), C-reactive protein (CRP) and rheumatoid factor (RF). Serum level of sclerostin and IL-Rawas measured using sandwich enzyme immunoassay (ELISA) technique (BIOMEDICA GRUPPE). The procedure was done according to the manufacturer instruction as supplied with in the kit for both patients and controls. $20 \mu \mathrm{l}$ standard/sample/control was added into appropriate wells followed by $50 \mu \mathrm{l}$ AB (biotinylated anti Sclerostin antibody or anti IL-Ra) then the wells were covered and incubated overnight (18-24h) at room temperature $\left(18-24^{\circ} \mathrm{C}\right)$ in the dark. Washing for 5 times was performed followed by adding $200 \mu \mathrm{l}$ conjugate and incubated for 1 hour at room temperature in the dark. After washing was performed $200 \mu \mathrm{l}$ substrate was added and incubated for $30 \mathrm{~min}$ at room temperature in the dark. $50 \mu \mathrm{l}$ stop solution was added and the 
absorbance was measured at $450 \mathrm{~nm}$ with reference $630 \mathrm{~nm}$.

\section{Statistical Analysis}

The Statistical Analysis System- SAS (2012) program was used to effect of difference factors in study parameters. Chisquare test was used to significant compare between percentage and Least significant difference -LSD test (T-Test) was used to significant compare between means in this study.

\section{Results and Discussion}

Table. 1 show comparison between patients and control group in erythrocyte sedimentation rate which show significant difference $(p<0.01)$ high level of ESR in patients than control group. Sclerostin level within normal range in healthy and patients but higher in healthy than patients with biological treatment which show significant difference $(p<0.05)$. Also IL-1Ra within normal range in healthy and patients but higher in healthy than patients with biological treatment which show significant difference $(p<0.05)$. ACCP result show nonsignificant difference between patients and healthy control.

Table 2: show comparison between patients and control in WBC and differential count of WBC which show significant difference between patients and control in WBC and neutrophil count $(\mathrm{p}<0.05)$ and nonsignificant difference in lymphocyte, monocyte, eosinophil, and basophil count between patients and control.

Table 3: show comparison between patients and control in RBC count, HB, HCT, RDW and PLT which show non-significant difference.
Table 4: show comparison between patients and control in $\mathrm{MCV}, \mathrm{MCH}, \mathrm{MCHC}$ and MPV which show non-significant difference.

Sclerostin, an inhibitor of the Wnt/ $\beta$-catenin pathway, has anti-anabolic effects on bone formation by negatively regulating osteoblast differentiation. Mutations in the human sclerostin gene (SOST) lead to sclerosteosis with progressive skeletal overgrowth, whereas sclerostin-deficient (Sost(-/-)) mice exhibit increased bone mass and strength.Therefore, antibody-mediated inhibition of sclerostin is currently being clinically evaluated for the treatment of postmenopausal osteoporosis in humans. Bone is constantly undergoing bone remodeling, a complex process involving the resorption of bone on a particular surface, followed by a phase of bone formation. In normal adults, and prior to menopause in females, there is a balance between the amount of bone resorbed by osteoclasts and the amount of bone formed by osteoblasts i.e. physiologic remodeling.

In patients with RA, this balance is altered in favor of resorption as a result of the inflammatory process, activation of osteoclasts and lack of bone repair. Accordingly, several negative clinical consequences occur in patients with RA (Walsh et al., 2004). Sclerostin,secretedbyan osteocyte and itencoded byprotein SOST gene, belongs to the DAN (differential screening selected gene aberrant in neuroblastoma) family of glycoproteins (van Bezooijen et al., 2007). Wnt pathway is important in the control of the bone formation by the regulation of osteoblast activity (Johnson et al., 2007). SOST is an important regulator of the Wnt pathway by blocking Wnt binding to its receptor and thereby inhibiting bone formation. The expression of Wnt antagonists such as secreted Frizzled- related protein-1 and 
sclerostin can be induced during inflammation and may also inhibit repair of bone erosion by suppressing bone formation (Schett et al., 2012). Blockage of Wnt antagonists such as sclerostin will trigger repair or even healing of bone erosion (Vis et al., 2011).

This is the first study in Iraq and the third study in the world that measured the level of sclerostin in patients with rheumatoid arthritis who receiving biological therapy. In current study there is significant difference between RA patients and control group On the contrary; Vis et al., (2014) found that sclerostin levels were significantly higher in female RA patients than healthy control Dutch females. This difference may be explained by the differences in the make-up of the study population and the difference in ethnicity.

Strategies of the current treatment, including early treatment with DMARDs, use of biologicals and newer DMARDs, and disease activity score (DAS) driven treat to target protocols of RA increased the number of patients achieving remission. Various studies indicated that a certain proportion of patients may reach remission regardless of the drugs administered to obtain disease control (William, 2004). Many of studies are currently exploring whether, after achieving remission, it is necessary to continue with an intense regimen either with expensive biologics or DMARD combinations. Flare was reported in approximately $26-40 \%$ of patients depending on the number of followup years, the types of drugs used to induce remission, and the minimum DMARD dosage used for maintenance. These findings underscore the need for markers to predict the sustainability of remission in RA patients.

IL-1Ra is a naturally occurring antiinflammatory molecule that inhibits the action of IL-1 induced pro-inflammatory activity and therefore has been shown to prevent joint erosion and damage in RA. Analysis of IL-1Ra in serum samples in our study showed reduction of the level of interleukin compared with control group. It has been reported that IL-1Ra is made by hepatocytes and by cells within the joint and behaves as an acute phase protein. TheIL-1 receptor antagonist (IL-1Ra) is a naturally occurring cytokine that inhibits the binding of IL-1 $\beta$ to IL-1R. IL-1Ra lacks the binding domain necessary for recruiting the IL- $1 \mathrm{R}$ accessory protein to the receptor complex; therefore, preventing downstream proinflammatory signaling.IL-1Ra has been given therapeutically in several experimental models of arthritis with dramatic effects (Horai et al., 2000).

Table.1 Compare between patients and control in ESR, SOST, IL-1Ra \& ACCP

\begin{tabular}{|c||c||c|c||c|}
\hline \multirow{2}{*}{ Group } & \multicolumn{4}{c|}{ Mean \pm SE } \\
\cline { 2 - 5 } & ESR & SOST & IL-1Ra & ACCP \\
\hline Patients & $31.23 \pm 11.18$ & $0.801 \pm 0.28$ & $0.633 \pm 0.35$ & $0.166 \pm 0.09$ \\
\hline \hline Healthy & $12.67 \pm 3.73$ & $1.072 \pm 0.59$ & $0.979 \pm 0.34$ & $0.226 \pm 0.11$ \\
\hline LSD value & $9.255 * *$ & $0.038 *$ & $0.209 *$ & $0.077 \mathrm{NS}$ \\
\hline \hline P-value & 0.0115 & 0.0492 & 0.0436 & 0.095 \\
\hline \hline \multicolumn{4}{|c|}{$*(\mathrm{P}<0.05), * *(\mathrm{P}<0.01)$, NS: Non-significant. } \\
\hline
\end{tabular}


Table.2 Compare between patients and control in WBC and Differential of WBC

\begin{tabular}{|c||c|c|c|c|c|c|}
\hline \multirow{2}{*}{ Group } & \multicolumn{7}{c|}{ Mean \pm SE } \\
\cline { 2 - 7 } & WBC & NEU & LYM & MONO & EOS & BASO \\
\hline Patients & $8.58 \pm 3.12$ & $5.34 \pm 2.78$ & $2.34 \pm 0.69$ & $0.619 \pm 0.17$ & $0.170 \pm 0.05$ & $0.0622 \pm 0.02$ \\
\hline \hline Healthy & $7.06 \pm 1.20$ & $4.28 \pm 1.09$ & $2.07 \pm 0.47$ & $0.457 \pm 0.15$ & $0.182 \pm 0.12$ & $0.0663 \pm 0.02$ \\
\hline \hline LSD value & $1.026 *$ & $0.772 *$ & $0.418 \mathrm{NS}$ & $0.288 \mathrm{NS}$ & $0.274 \mathrm{NS}$ & $0.0219 \mathrm{NS}$ \\
\hline \hline P-value & 0.0339 & 0.0286 & 0.263 & 0.405 & 0.279 & 0.336 \\
\hline
\end{tabular}

Table.3 Compare between patients and control in RBC, HGB, HCT,

RDW \& PLT

\begin{tabular}{|c|c|c|c|c|c|}
\hline \multirow{2}{*}{ Group } & \multicolumn{5}{|c|}{ Mean \pm SE } \\
\cline { 2 - 6 } & RBC & HGB & HCT & RDW & PLT \\
\hline \hline Patients & $4.77 \pm 0.59$ & $12.59 \pm 2.24$ & $37.73 \pm 5.67$ & $12.39 \pm 2.77$ & $271.98 \pm 42.40$ \\
\hline Healthy & $4.83 \pm 0.54$ & $13.34 \pm 1.76$ & $38.07 \pm 4.12$ & $11.87 \pm 1.22$ & $266.23 \pm 31.29$ \\
\hline LSD value & $0.437 \mathrm{NS}$ & $1.095 \mathrm{NS}$ & $3.552 \mathrm{NS}$ & $1.668 \mathrm{NS}$ & $46.502 \mathrm{NS}$ \\
\hline \hline P-value & 0.694 & 0.216 & 0.253 & 0.107 & 0.489 \\
\hline \hline
\end{tabular}

Table.4 Compare between patients and control in MCV, MCH, MCHC \& MPV

\begin{tabular}{|c|c||c|c||c|}
\hline \multirow{2}{*}{ Group } & \multicolumn{4}{|c|}{ Mean \pm SE } \\
\cline { 2 - 5 } & MCV & MCH & MCHC & MPV \\
\hline Patients & $79.37 \pm 9.39$ & $26.51 \pm 3.94$ & $42.90 \pm 9.67$ & $6.73 \pm 1.53$ \\
\hline Healthy & $78.34 \pm 5.73$ & $27.67 \pm 2.82$ & $34.97 \pm 1.52$ & $7.38 \pm 1.68$ \\
\hline \hline LSD value & $12.782 \mathrm{NS}$ & $7.201 \mathrm{NS}$ & $10.805 \mathrm{NS}$ & $1.694 \mathrm{NS}$ \\
\hline P-value & 0.573 & 0.984 & 0.0859 & 0.361 \\
\hline \hline \multicolumn{5}{|c}{ NS: Non-significant. } \\
\hline
\end{tabular}

More importantly, these treatments have demonstrated efficacy in $60 \%$ of RA patients. A significant body of experimental evidence has implicated the proinflammatory cytokine IL-1 in the pathogenesis of RA. For example, IL-1b over expression in rabbit knee joints causes arthritis with clinical and histological features characteristic of RA, whereas IL-1 deficiency is associated with reduced joint damage. In experimental models, IL-1 blockers, including IL-1 receptor antagonist (IL-1Ra), significantly reduce clinical and histological disease parameters. In RA patients, plasma and synovial fluid concentrations of IL-1 are elevated, and these correlate with various parameters of disease activity. The production of endogenous IL-1Ra, however, appears to be insufficient to balance these higher IL-1 
levels. The efficacy of blocking IL-1 in patients with active RA has been established in controlled clinical trials of anakinra, a recombinant human IL- $1 \mathrm{Ra}$ (r-metHuIL1ra). When used alone or in combination with methotrexate, anakinra significantly reduces the clinical signs and symptoms of RA compared with placebo. Taken together, these results indicate that IL-1 plays an important role in the pathogenesis of RA.

IL-1 and IL-1Ra production has been evaluated in tissue culture using synovial cells isolated from RA patients. In one study, spontaneous IL-1Ra production predominated in one-third of the synovial specimens; however, in the other two-thirds, IL-1 was produced in higher amounts than IL-1Ra. In another study, synovial cells produced 1.2 to 3.6 times higher amounts of IL-1Ra than IL-1. Purified synoviocytes from these specimens contained IL-1Ra but secreted very low amounts.

In mice, IL-1Ra gene deletion resulted in the spontaneous development of a chronic polyarthropathy, which was dependent on the genetic background of the mice. In BALB/cA mice, $80 \%$ developed arthritis by 8 weeks of age, and all animals had disease by 16 weeks of age. In comparison, only $15 \%$ of C57BL/6J mice had developed arthritis by 32 weeks. The polyarthritis in BALB/cA mice was characterized by synovial hyperplasia, leucocyte infiltration and erosive pannus formation. IL-1 levels were increased 10-fold in the IL-1Radeficient animals compared with wild-type controls, whereas TNF levels were only slightly increased. In another series of IL1Ra-deficient mice with a genetic background different from that of the mice in the previous study. Recent studies have described the spontaneous development of arthritis or vasculitis in IL-1 receptor antagonist (IL-1Ra) knockout mice bred on specific and different genetic backgrounds. The levels of both secreted and intracellular isoforms of IL-1Ra produced in the rheumatoid joint or in the arterial wall may not be adequate to effectively inhibit the excess amounts of locally produced IL-1. Thus, an imbalance between IL-1 and IL$1 \mathrm{Ra}$ may predispose to local inflammatory disease in particular tissues in the presence of other as yet unknown genetically influenced factors.

\section{References}

Aletaha, D., Neogi, T., Silman, A.J., Funovits, J., Felson, D.J., et al. 2010. Rheumatoid arthritis classification criteria: an American college of rheumatology/ European league against rheumatism collaborative initiative. Arthritis Rheum., 62(9): 2569-81.

Appel, H., Ruiz-Heiland, G., Listing, J., Zwerina, J., Herrmann, M., Mueller, R., et al. 2009. Altered skeletal expression of sclerostin and its link to radiographic progression in ankylosing spondylitis. Arthritis Rheum., 60: pp. 3257-3262.

Barnabe, C., Homik, J., Barr, S.G., Martin, L., Maksymowych, W.P. 2014. The effect of different remission definitions on identification of predictors of both point and sustained remission in rheumatoid arthritis treated with anti-TNF therapy. J. Rheumatol., 41: 1607-13.

Blom, A.B., van Lent, P.L., van der Kraan, P.M., van den Berg, W.B. 2010. To seek shelter from the WNT in osteoarthritis? WNT-signaling as a target for osteoarthritis therapy. Curr. Drug Targets, 11: 620-629.

Eggelmeijer, F., Papapoulos, S.E., Westedt, M.L., et al. 1993. Bone metabolism in rheumatoid arthritis; relation to disease activity. Br. J. Rheumatol., 32: 387-391.

Horai, R., Saijo, S., Tanioka, H. et al. 2000. Development of chronic inflammatory arthropathy resembling rheumatoid 
arthritis in interleukin 1 receptor antagonist-deficient mice. J. Exp. Med., 191: 313-20.

Hu, J., Li, H., Chi, G., Yang, Z., Zhao, Y., Liu, W., Zhang, C. 2015. IL1RA gene-transfected bone marrowderived mesenchymal stem cells in APA microcapsules could alleviaterheumatoid arthritis. Int. J. Clin. Exp. Med., 8(1): 706-13.

Ismail, E., Nofal, O.K., Sakthiswary, R., Shaharir, S.S., Sridharan, R. 2016. The Clinical Significance of Interleukin1 Receptor Antagonist +2018

Polymorphism in Rheumatoid Arthritis. PLoS One, 11(4): e0153752.

Johnson, M.L. and Kamel, M.A. 2007. TheWnt signaling pathway and bone metabolism. Curr. Opin. Rheumatol., 19: 376-382.

Jolles, B.M. and Bogoch, E.R. 2002. Current consensus recommendations for rheumatoid arthritis therapy: A blind spot for osteoporosis prevention and treatment. J. Rheumatol., 29: 18141817.

Matzelle, M.M., Gallant, M., Condon, K.W., et al. 2012. Resolution of inflammation induces osteoblast function and regulates the Wnt signaling pathway. Arthritis Rheum., 64: 1540-1550.

Power, J., Poole, K.E., van Bezooijen, R., Doube, M., Caballero-Alias, C., Lowik, A.M., et al. 2010. Sclerostin and the regulation of bone formation: effects in hip osteoarthritis and femoral neck fracture. J. Bone Miner. Res., 25: pp. 1867-1876.

Schett, G. and Gravallese, E. 2012. Bone erosion in rheumatoid arthritis: mechanisms, diagnosis and treatment.
Nat. Rev. Rheumatol., 8: 656-664.

Taylor, W.J., Harrison, A.A., Highton, J., Chapman, P., Stamp, L., Dockerty, J. et al. 2008. Disease Activity Score 28ESR bears a similar relationship to treatment decisions across different rheumatologists, but misclassification is too frequent to replace physician judgement. Rheumatol., (oxford). 47(4): 514-8.

van Bezooijen, R.L., Svensson, J.P., Eefting, D., et al. 2007. Wht but not BMP signaling is involved in the inhibitory action of sclerostin on BMP-stimulated bone formation. J. Bone Miner. Res., 22: 19-28.

van der Woude, D., Visser, K., Klarenbeek, N.B., Ronday, H.K., Peeters, A.J., Kerstens, P.J., et al. 2012. Sustained drug-free remission in rheumatoid arthritis after DAS-driven or non-DASdriven therapy: a comparison of two cohort studies. Rheumatol., (Oxford), 51: $1120-8$.

Vis, M., Britsemmer, K., Heijboer, A.C., et al. 2011. Sclerostin Levels in Rheumatoid Arthritis and Its Relationship to Disease Activity and Radiographic Joint Damage. Arthritis Rheum., 63: 1799.

Walsh, N.C. and Gravallese, E.M. 2004. Bone loss in inflammatory arthritis: mechanisms and treatment strategies. Curr. Opin. Rheumatol., 16: 419-427.

William, P.A. and Cem Gabay. 2002. Physiologic role of interleukin-1 receptor antagonist. Arthritis Res. Ther., 245.

Wolfe, F. 2002. The psychometrics of functional status questionnaires: room for improvement. J. Rheumatol., 29: $865-8$.

\section{How to cite this article:}

Sanan Th. Abdalwahab, Haider Sabah Kadhim, Alauldeen Mudhafar Zubair Alqasim and Faiq I. Gorial. 2016. Sclerostin and IL-1Ra in Rheumatoid Iraqi Patients after Biological Therapy. Int.J.Curr.Microbiol.App.Sci. 5(9): 718-724. doi: http://dx.doi.org/10.20546/ijcmas.2016.509.082 